\title{
PENGARUH PEMBERIAN KREDIT DAN FAKTOR - FAKTOR YANG MEMPENGARUHI PRODUKSI USAHA SAPI PERAH
}

\author{
D. Firmansyah ${ }^{1}$, A. Arsyad $^{1 \mathrm{a}}$, W. Nahraeni ${ }^{1}$ \\ ${ }^{1}$ Jurusan Agribisnis, Fakultas Pertanian Universitas Djuanda Bogor \\ Jalan Tol Ciawi No. 1 Kotak Pos 35 Bogor 16720 \\ a'Korespondensi: Apendi Arsyad, Telp: 08129347542, Email:apendi.arsyad@unida.ac.id
}

\begin{abstract}
Capital is one of the main problems found in cow farming business. This is caused by the low provision of financial credit to animal farming sector. This study was conducted in Riung Gunung Farmer Group. Thirty-nine cow farmers were selected as respondents by using a census method. The study was aimed at assessing the effect of financial credit provision on cow production. Other factors affecting the production, financial institution, and financial credit distribution were also assessed. A descriptive analysis, Cobb-Douglas production function, and income analysis were used. Results showed that the amount of financial credit, the amount of concentrate feed, the amount of roughage, and lactation period were found as significant factors at $\alpha$ levels of 0.01 and 0.3 . It was also found that the average farmers' income within a lactation period was $\mathrm{Rp} 49,852,322$ and the R/C over total cost was 1.74 indicating this cow farming business was profitable and feasible. The Cob Douglas production function parameters resulted in a value of 1.222 indicating that this business was in the scale of increasing return. This also indicated that this business could give higher production and higher profit. It was concluded that financial credit institution system in cooperation with KPSBU played a very significant role on the development of production, institution, marketing, capital, and technology.
\end{abstract}

Key words : Cow financial credit, Cobb Douglas, credit institution

\begin{abstract}
ABSTRAK
Permasalahan utama dalam usaha sapi perah yaitu permodalan yang salah satu disebabkan oleh rendahnya penyaluran kredit ke sektor peternakan. Hal ini menyebabkan usaha sapi perah masih berkala kecil atau usaha rakyat dengan skala usaha $1-3$ ekor. Penelitian ini bertujuan untuk mengetahui pengaruh pemberian kredit terhadap usaha ternak sapi perah dan menganalisis faktor - faktor yang mempengruhi pendapatan peternak serta mengevaluasi sistem kelembagaan dan pelaksanaan kredi. Penelitian ini menggunakan analisis deskriptif, fungsi produksi Cobb-Doulas dan analisis pendapatan. Hasil analisis pengaruh pemberian kredit terhadap peningkatan pendapatan dengan beberapa faktor produksi adalah jumlah konsentrat, jumlah pakan hijauan, dan masa laktasi berpengaruh nyata pada taraf $\alpha: 0,2$ atau nyata pada selang kepercayaan $80 \%$. Berdasarkan hasil rata rata penerimaan peternak dalam satu periode yaitu Rp. 49.852.322, 49 dan memiliki R/C 1,74 sehingga usaha ternak sapi perah menguntungkan dan layak untuk diusahakan karena $\mathrm{R} / \mathrm{C}$ lebih dari satu. Sistem kelembagaan dilapangan yang terjadi pada usaha sapi perah terdapat empat sitem akan tetapi sistem kelembagaan kredit yang paling mudah dan singkat adalah sistem kredit sapi bergulir mandiri program KPSBU dan yang paling sulit adalah sistem kredit program perbankan.
\end{abstract}

Kata Kunci : Kredit Sapi Perah, Kelembagaan Kredit, Analisis Faktor Produksi 


\section{PENDAHULUAN}

Peternakan merupakan subsektor yang memiliki peluang besar untuk dikembangkan karena kebutuhan masyarakat akan produk hasil peternakan meningkat setiap tahunnya seiring dengan meningkatnya pertumbuhan penduduk (Direktorat Jenderal Peternakan. 2008).

Rendahnya produksi susu di Indonesia dipengaruhi oleh keterbatasan modal yang dimiliki peternak dan berakibat pada faktor - faktor produksi seperti konsentrat, pakan hijauan serta ketersediaan sumber bibit sapi perah dengan kualitas yang baik. Selain itu, sifat genetik sapi yang menurun dan rendahnya penanganan penyakit pada sapi perah menjadi faktor lain yang menjadi penyebab rendahnya produksi susu.

Permasalahan utama usaha sapi perah adalah sebagian besar masih berskala kecil atau usaha rakyat. Faktor utamanya adalah keterbatasan modal dalam pengembangan usaha. Beberapa indikator penyebab terjadinya keterbatasan modal yaitu sulitnya aksesibilitas kredit bagi peternak, tidak adanya anggunan serta sistem pembayaran yang kurang sesuai dengan usaha ternak sehingga membuat peternak kesulitan dalam menjalankan dan mengembangkan usahanya.

Masih rendahnya penyaluran kredit ke sektor peternakan disebabkan oleh keadaan internal peternak yang memiliki kendala dalam kemampuan pengembalian kredit dan tidak adanya jaminan kredit serta dari sisi lembaga penyalur keuangan juga masih memiliki kekhawatiran akan tingginya potensi terjadinya default atau kredit macet karena sifat produksi di sektor peternakan atau pertanian berpola musiman. Hal ini menyebabkan perbankan cenderung menahan diri dalam melakukan penyaluran kredit ke sektor pertanian atau peternakan. Dimana fakta dilapanagan program Kredit Cinta Rakyat (KCR) Usaha Mikro dan Kecil yang diluncurkan tahun 2011 dengan dana mencapai Rp. 165 miliar dari APBD Provinsi Jawa Barat akan tetapi baru tersalurkan Rp. 62 miliar atau 32,57 \% dari dana yang telah disiapkan. (Disnak Provinsi Jawa Barat, 2012).

Modal merupakan faktor penunjang kelancaran usaha ternak, akan tetapi sumber dan jenis permodalan menjadi kendala. Dalam penyaluran sistem kredit terkadang pembayaran kredit menjadi masalah baru bagi peternak. Jenis kredit yang berlaku akan memiliki dampak terhadap pelaksanaan usahatenak, mengingat modal usaha peternak relatif rendah maka jenis kredit dengan sistem bergulir sapi perah merupakan salah satu alternatif solusi dalam meminimalisir penyalahgunaan kredit. (Suandari, 2009).

Secara umum, penelitian ini memiliki tujuan yaitu (1) Mengetahui dan mempelajari profil peternak penerima kredit di kelompok ternak Riung Gunung (2) Menganalisis faktor - faktor yang mempengaruhi peningkatan pendapatan peternak sapi perah di kelompok ternak Riung Gunung (3) Mengevaluasi pemberian kredit sapi perah terhadap keberhasilan usaha peternak sapi perah di kelompok ternak Riung Gunung (4) Mengevaluasi sistem kelembagaan dan pelaksanaan kredit sapi perah yang terjadi di kelompok ternak Riung Gunung dan Koperasi KPSBU.

\section{BAHAN DAN METODE}

\section{Usaha Ternak Sapi Perah}

Pengembangan usaha peternakan sapi perah mempunyai dampak positif terhadap pembangunan peternakan di Indonesia karena dapat : 1) menghemat devisa negara, 2) menciptakan lapangan kerja, 3) meningkatkan pendapatan peternak, dan 4) perbaikan gizi nasional (Sudono, 1999).

\section{Kredit}

Kredit berasal dari bahasa latin "credere" yang berarti kepercayaan, karena itu dasar kredit adalah kepercayaan. Dengan demikian seseorang yang memperoleh kredit pada dasarnya adalah memperoleh kepercayaan, atau dengan 
kata lain orang yang mendapat bantuan kredit adalah mereka yang telah mendapat kepercayaan untuk dapat membayar lunas pinjamannya dalam jangka waktu tertentu (Suyatno, 2003).

\section{Fungsi Produksi}

Fungsi produksi adalah hubungan fisik antara masukan produksi (input) dan produksi (Doll dan Orazem, 1984). Untuk menunjukan total produksi yang dihasilkan dari pemakaian faktor-faktor produksi, maka kurva produksi total dapat dibedakan menjadi tiga daerah produksi untuk memberikan gambaran nilai elastisitas produksi yang diperoleh dari suatu proses produksi Gambar 1.
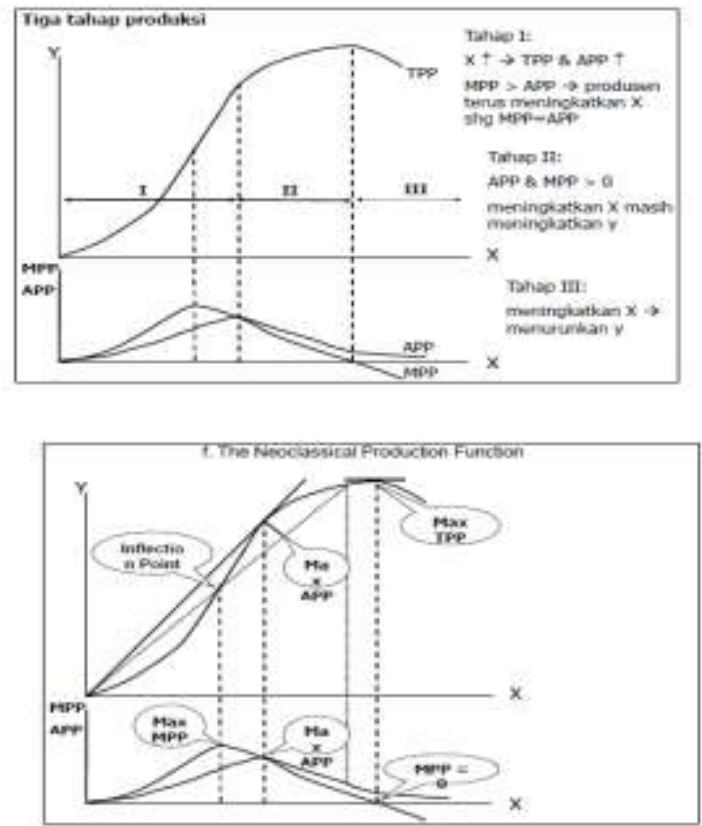

Gambar 1. Daerah Produksi dan Elastisitas produksi (Doll dan Orazem, 1984).

Keterangan :

Y : Produksi

X : Faktor - Faktor Produksi

PT : Produk Total

PM : Produk Marginal

PR : Produk rata - rata

Secara matematik, fungsi Cobb-Doglas dapat dituliskan dengan persamaan :

$\mathrm{Y}=a X_{1}{ }^{\mathrm{b} 1} \mathrm{X}_{2}^{\mathrm{b} 2} \ldots \mathrm{X}_{\mathrm{i}}^{\mathrm{bi}} \ldots \mathrm{X}_{\mathrm{n}}^{\mathrm{bn}} \mathrm{e}^{\mathrm{u}}$

$\mathrm{Y}=\mathrm{a} \pi \mathrm{X}_{\mathrm{i}}^{\mathrm{bi}} \mathrm{e}^{\mathrm{u}}$
Bila fungsi Cobb-Doglas tersebut di nyatakan dengan persamaan linear, dapat ditulis ke salah satu fungsi produksi yang sering digunakan yaitu fungsi produksi :

$\ln Y=\ln a+b 1 \ln X_{1}+b 2 \ln X_{2 \ldots} b_{n} \ln X_{n}^{+e}$

Di mana :

$\mathrm{Y}$ : variabel terikat

$\mathrm{X}_{\mathrm{i}}$ : variabel bebas

a : konstanta

b : parameter dugaan

$b_{i}$ : koefisien regresi

$\mathrm{u}$ : kesalahan (disturbance term)

e : logaritma natural, $\mathrm{e}=2,718$

Untuk menghitung elastisitas produksi maka digunakan rumus,

$$
\begin{array}{r}
P M=\frac{\text { Tambahan output }}{\text { Tambahan input tertentu }} \\
=\frac{\Delta Y}{\Delta X i}=f^{\prime} Y \\
P R=\frac{\text { Output total }}{\text { Input total tertentu }}=\frac{X}{Y i}
\end{array}
$$

$\mathrm{E}_{\mathrm{p}}$ ini secara matematis dapat dirumuskan sebagai berikut :

$\mathrm{E}_{\mathrm{p}}=\frac{\partial y}{\partial x i} \cdot \frac{X i}{Y}=\frac{P M}{P R}$

\section{Analisis Pendapatan}

Menurut Soekartawi (2006), pendapatan didefinisikan sebagai selisih total penerimaan yang diperoleh dengan total biaya yang dikeluarkan pada suatu kegiatan produksi. Pendapatan dalam usahatani dirumuskan sebagai berikut :

$$
\begin{aligned}
\Pi & =\mathrm{TR}-\mathrm{TC} \\
\mathrm{TR} & =\mathrm{P} \times \mathrm{Y} \\
\mathrm{TC} & =\mathrm{TFC}+\mathrm{TVC}
\end{aligned}
$$

Keterangan :

$$
\begin{array}{ll}
\pi & =\text { Pendapatan } \\
\text { TR } & =\text { Total Penerimaan } \\
\text { TC } & =\text { Total Biaya } \\
\mathrm{P} & =\text { Harga Satuan Produk } \\
\text { Y } & =\text { Total Produk } \\
\text { TFC } & =\text { Total Biaya Tetap } \\
\text { TVC } & =\text { Total Biaya Variabel }
\end{array}
$$


Lokasi dan Waktu Penelitian

Penelitian dilakukan di Desa Cicadas Kecamatan Sagalaherang Kabupaten Subang karena terdapat kelompok ternak yang menjalankan kredit sistem bergulir yaitu kelompok ternak Riung Gunung yang bekerjasama dengan KPSBU. Penelitian dilakukan pada April Juni 2013.

\section{Jenis dan Sumber Data}

Jenis data pada penelitian ini yaitu data primer dan data sekunder. Sumber data primer diperoleh melalui wawancara langsung terhadap responden dengan menggunakan daftar pertanyaan (kuesioner) yang telah disediakan. Data sekunder diperoleh dari berbagai sumber seperti jurnal ilmiah, buku, penelitian terdahulu dan literatur pendukung lainnya. Data yang dikumpulkan yang bersifat kuantitatif baik primer maupun sekunder akan diolah dengan program Microsoft excel dan software SPSS 20 for windows, sedangkan data yang bersifat kualitatif diuraikan dalam bentuk deskriptif dengan cara tabulasi.

\section{Metode Pengambilan Sampel}

Metode pengambilan sampel peternak dilakukan dengan metode sensus dengan jumlah 39 sampel berdasarkan jumlah anggota kelompok ternak Riung Gunung.

\section{Analisis Deskriptif}

Analisis deskriptif adalah suatu metode dalam meneliti status kelompok manusia, suatu objek, kondisi, sistem pemikiran, ataupun suatu kelas peristiwa pada masa sekarang. (Natzir, 1999). Analisis secara deskriptif dengan cara tabulasi dilakukan untuk menjawab tujuan penelitian dalam menganalisis bentuk dan pelaksaan kredit serta menjelaskan gambaran umum koperasi dan kelompok ternak yang meliputi informasi kondisi geografi wilayah, iklim, kondisi penduduk, serta keadaan sarana dan prasarana penunjang usaha ternak sapi perah.

\section{Model Cobb-Douglas}

Dalam panel ini digunakan model fungsi produksi Cobb - Douglas, secara matematik dapat dituliskan dengan persamaan :

$\ln \mathrm{Y}=\ln \mathrm{a}+\mathrm{b} 1 \ln \mathrm{X}_{1}+\mathrm{b} 2 \ln \mathrm{X}_{2}+\mathrm{b} 3 \ln \mathrm{X}_{3}$ $+\mathrm{b} 4 \ln \mathrm{X}_{4}+\mathrm{b} 5 \ln \mathrm{X}_{5}+\mathrm{b} 6 \ln \mathrm{X}_{6}$

Di mana :

Y : Produksi

$\mathrm{X}_{1}$ : Kepemilikan jumlah kredit sapi perah (ekor)

$\mathrm{X}_{2}$ : Jumlah Konsentrat (kg)

$\mathrm{X}_{3}$ : Jumlah Pakan Hijauan (kg)

$\mathrm{X}_{4}$ : Masa Laktasi (bulan)

$\mathrm{X}_{5}$ : Pendidikan (tahun)

$\mathrm{X}_{6}$ : Pengalaman (tahun)

a : Konstanta

b : Parameter dugaan

$\mathrm{u}$ : Kesalahan (disturbance term)

e : Logaritma natural, e $=2,718$

\section{HASIL DAN PEMBAHASAN}

\section{Lokasi Dan Keadaan Umum Kabupaten} Subang

Desa Cicadas berada pada ketinggian $530-780$ meter di atas permukaan laut dengan rata-rata suhu udara $30,4^{\circ} \mathrm{C}$ dengan iklim tropis. Penduduk Desa Cicadas sebagian besar bermata pencaharian dibidang pertanian, baik di lahan milik sendiri (berperan sebagai petani pemilik) ataupun dilahan milik orang lain (berperan sebagai buruh tani). Penduduk lainnya bermata pencaharian sebagai peternak, karyawan, pedagang dan PNS.

\section{Sejarah dan kegiatan Kelompok Ternak Riung Gunung}

Kelompok ternak Riung Gunung merupakan kelompok peternak sapi perah yang berada di kampung Cigeureung Desa Cicadas Kecamatan Sagalaherang Kabupaten Subang. Kelompok ternak Riung Gunung sudah terdaftar secara resmi di Dinas Peternakan Kabupaten Subang pada tanggal 10 Februari 2003, kelompok ini awalnya terbentuk atas inisiatif dari anggota dengan jumlah 17 
peternak dengan adanya arahan dari Dinas Peternakan Kabupaten Subang.

Karakteristik peternak penerima kredit yang ada di kelompok ternak Riung Gunung rata-rata menunjukan tingkat umur berkisar $27-61$ tahun dengan kisaran terbanyak pada usia 27 - 32 tahun dengan 38,46\%. Dengan mayoritas tingkat pendidikan SD sebanyak 29 orang atau $74.36 \%$, jumlah tanggungan keluarga sebanyak 3 orang yaitu sebanyak 16 peternak atau $41,03 \%$ dan pengalaman $6-$ 10 tahun sebanyak 30 orang atau $76.92 \%$ serta kepemilikan jumlah kredit sapi perah 1- 3 ekor sebanyak 36 orang atau $92,31 \%$ dan kepemilikan jumlah pribadi sapi perah 1- 3 ekor sebanyak 28 orang atau $71,79 \%$.

Faktor - faktor yang mempengaruhi dalam peningkatan pendapatan usaha ternak sapi perah pada awalnya diduga bahwa ada sepuluh variabel yaitu kepemilikan jumlah kredit sapi perah, jumlah konsentrat, jumlah pakan hijauan, jumlah kandang, masa laktasi, biaya pemeliharaan, harga susu, usia, pendidikan, dan pengalaman. Setelah dilakukan analisis secara mendalam melalui perhitungan regresi berganda diduga ditemukan adanya multikolinearitas pada variabel sehingga ada beberapa variabel yang dikurangi dalam perhitungannya dengan menggunakan tahapan stepwise. Berdasarkan hasil pendugaan analisis regresi berganda bahwa hasil dari model summary memiliki nilai $\mathrm{R}=0,977$ dan koefisien determinasi ( $\left.\mathrm{R}_{\text {square }}\right)$ sebesar 0,955 berarti 95,5 \% keragaman produksi dapat dijelaskan oleh keragaman faktor faktor produksi dan sisanya 4,5\% dijelaskan oleh variabel lain yang tidak dimasukkan kedalam model yaitu kemungkinan jumlah kandang, biaya operasional, usia atau iklim.

Hasil dari uji Anova dihasilkan nilai $\mathrm{F}=113.789$ dan model nyata pada taraf $\alpha=0,2$ atau nyata pada selang kepercayaan $80 \%$ yang lebih besar dari nilai F-tabel sebesar 1,303. Sehingga dapat dihipotesiskan bahwa variabel independent berarti secara bersamaan yaitu jumlah kredit sapi, konsentrat, masa laktasi, pakan hijauan, pendidikan dan pengalaman berpengaruh nyata terhadap produksi susu.

Hasil uji t yaitu hasil uji secara sendiri-sendiri menghasilkan variabel bebas yang nyata secara statistik. Variabel yang berpengaruh nyata secara statistik yaitu konsentrat dan jumlah pakan hijauan serta masa laktasi. Tercantum pada Tabel 1.

Tabel 1. Hasil Pendugaan Fungsi Produksi Cobb-Douglas

\begin{tabular}{lcccccc}
\hline \multicolumn{1}{c}{ Model } & B & Std. Error & Beta & T & Sig & VIF \\
\hline (Constant) & -.114 & .680 & & -.168 & .868 & \\
Kredit Sapi & .061 & .057 & .058 & 1.074 & .291 & 2.060 \\
Konsentrat & .443 & .049 & .537 & 8.963 & ${ }^{* * * *} .000$ & 2.565 \\
Masa Laktasi & .360 & .268 & .055 & 1.341 & ${ }^{* *} .190$ & 1.185 \\
Pakan Hijauan & .458 & .048 & .489 & 9.607 & ${ }^{* * * *} .000$ & 1.854 \\
Pendidikan & -.005 & .070 & -.003 & -.074 & .941 & 1.145 \\
Pengalaman & .019 & .065 & .014 & .299 & .767 & 1.476 \\
$\mathrm{R}^{2}$ & 0,955 & & & & & \\
F hitung & 113.789 & & & & & \\
\hline
\end{tabular}

Keterangan :

*** : Berpengaruh nyata pada taraf

nyata $\alpha=0,01$ atau $1 \%$

** : Berpengaruh nyata pada taraf

nyata $\alpha=0,2$ atau $20 \%$

Pengaruh pemberian kredit sapi perah terhadap kerhasilan usaha ternak dapat terlihat dari hasil analisis pendapatan usaha ternak. Berdasarkan Lampiran 1. yaitu tabel penerimaan produksi bahwa rata - rata peternak memiliki 4 ekor sapi perah mendapatkan penerimaan $\mathrm{Rp}$. 49.852.322,49 dengan laba bersih $\mathrm{Rp}$. 21.212.667,36 maka diperoleh R/C 1,74 
berarti usaha ternak dengan skala kepemilikan 4 ekor dapat dijalankan.

\section{Kredit Sapi Perah Sistem Bergulir Pemerintah}

Kelompok Ternak Riung Gunung menjalankan usaha sapi perah dengan sistem kredit sapi bergulir senilai Rp. 201.250.000 yang kemudian dibelikan sapi perah menjadi 50 ekor dan disalurkan kepada peternak langsung berupa sapi untuk kemudian dikelola oleh para peternak yang menjadi anggota Kelompok Ternak Riung Gunung dengan perjanjian tingkat pengembalian 60 persen berbanding 40 persen dengan jangka waktu antara 3 - 6 tahun kedepan dengan dua keturunan atau dua ekor sapi.

\section{Program Kredit Sapi Bergulir Mandiri KPSBU dan Pihak Swasta}

Seiring berjalannya waktu kerjasama antara Kelompok Ternak Riung Gunung dengan KPSBU bekerjasama dalam memasarkan hasil susu maka anggota kelompok mendapat kesempatan dalam program sapi bergulir secara mandiri dari KPSBU dan secara kerjasama dengan pihak perusahaan swasta yaitu PT Danone dengan sistem pembayaran setiap 2 kali dalam sebulan yaitu setiap 15 hari yang dipotong dari hasil produksi susu yang disetorkan kepada KPSBU dalam jangka waktu 3 - 5 tahun sesuai perjanjian di awal antara peternak dengan pengelola yaitu PT. Sahabat Cipta akan tetapi proses pembayaran angsuran dikelola oleh KPSBU. Sistem kredit seperti ini diberikan kemudahan karena tidak adanya jaminan bagi peternak kepada pihak pemberi pinjaman akan tetapi tetap memiliki risiko yaitu ketika sapi mati sebelum lunas masa kredit maka peternak harus terus membayar sisa kredit yang belum selesai.

\section{Program Kredit PerBankan}

Adapun sistem kredit melalui perbankan memiliki risiko yang tinggi karena memiliki tingkat suku bunga tinggi yaitu sebesar 6 persen pertahun dan harus memiliki agunan yang biasanya berupa sertifikat tanah. Bentuk kredit yang diberikan berupa uang dengan sistem pembayaran dicicil dengan bentuk pengembalian dibayar dengan uang. Prosedur pencairan kredit oleh pihak Bank sangat rumit karena harus mendapatkan rekomendasi dari Dinas Peternakan kemudian akan di verifikasi dan validasi oleh pihak bank, selain itu jumlah besaran kredit terkadang tidak sesuai dengan pengajuan dikarenakan disesuaikan dengan nilai jual agunan yang diagunkan kepada pihak bank.

Tabel 2. Perbedaan Sumber Kredit Antara Pemerintah, KPSBU, Bank, dan Pihak Swasta

\begin{tabular}{lllll}
\hline \multirow{2}{*}{ Jenis } & \multicolumn{4}{c}{ Sumber Kredit } \\
\cline { 2 - 5 } & Pemerintah & KPSBU & PT Danone & Bank \\
\hline Bentuk kredit & Sapi & Sapi & Sapi & Uang \\
Jaminan & - & - & - & Sertifikat \\
& & & Tanah \\
Bentuk Pengembalian & Sapi/Uang & Susu & Susu & Uang \\
Cara Penegmbalian & Dicicil & Setor Susu & Setor Susu & Dicicil \\
Sistem Pembayaran & Keturunan & Perhari & Perhari & \\
& Sapi $(60 \%:$ & Perbuli & 2 kali & Setor \\
Bunga kredit & $40 \%)$ & & Perbulan & Perbulan \\
Jangka waktu & - & - & & \\
Biaya administrasi & $3-6$ tahun & $3-5$ tahun & $3-5$ tahun & $3-5$ tahun \\
Prosedur & - & - & - & Ada \\
& Mudah & Mudah & Biasa & Sulit \\
\hline
\end{tabular}


Kelebihan dari sumber kredit sistem bergulir pemerintah, KPSBU dan PT Danone untuk anggota kelompok yang telah menjadi anggota KPSBU yaitu mendapatkan pelayanan kesehatan hewan, inseminasi buatan, penyuluhan dan jaminan kesehatan dengan mendapatkan kartu kesehatan sebanyak 5 kartu pertahun dan nilai masing - masing kartu sebesar Rp. 25.000. Selain itu juga mendapat kesempatan melakukan pinjaman uang tanpa bunga dan anggunan serta mendapat kesempatan bantuan kandang percontohan dan biogas.

\section{Keuntungan Bermitra dengan KPSBU}

Keuntungan bermitra dengan

KPSBU bagi peternak yaitu sesuai kebutuhan usaha ternak seperti input produksi dan kebutuhan bagi peternak seperti kebutuhan pokok dan jaminan kesehatan. Keuntungan- keuntunga lainnya nnya dapat dilihat pada Tabel 3.

Tabel 3. Keuntungan Bermitra dengan KPSBU

\begin{tabular}{|c|c|c|c|c|}
\hline No & Uraian & $\begin{array}{l}\text { Sebelum } \\
\text { Bermitra }\end{array}$ & $\begin{array}{l}\text { Sesudah } \\
\text { Bermitra }\end{array}$ & Keterangan \\
\hline 1 & Mendapat kesempatan kredit sapi & ! & $\checkmark$ & Sistem Bergulir KPSBU \\
\hline 2 & Pelayanan Kesehatan Hewan & - & $\checkmark$ & Gratis \\
\hline 3 & IB & - & $\checkmark$ & Gratis \\
\hline 4 & Pelatihan dan Penyuluhan & - & $\checkmark$ & Gratis \\
\hline 5 & Pemasaran & - & $\checkmark$ & Dijamin $100 \%$ \\
\hline 6 & Suplay konsentrat & - & $\checkmark$ & $100 \%$ sesuai kebutuhan \\
\hline 7 & Mendapatkan Pinjaman Uang & - & $\checkmark$ & Tanpa bunga \\
\hline 8 & Pelayanan Poliklinik & - & $\checkmark$ & Mendapat kartu sehat gratis \\
\hline 9 & $\begin{array}{l}\text { Mendapat kesempatan kredit PT } \\
\text { Danone }\end{array}$ & - & $\checkmark$ & Sistem bergulir \\
\hline 10 & Kredit waserda & - & $\checkmark$ & Kebutuhan pokok \\
\hline
\end{tabular}

Keteranagan :

- : Tidak mendapat pelayanan

$\checkmark$ : Mendapatkan pelayan

Tingkat Kepuasan Peternak Terhadap Pelayanan KPSBU

Berdasarkan tabel 4, tingkat kepuasan pada tingkat suku bunga memiliki nilai indeks tertinggi yaitu 38 , pada urutan kedua nilai indeks besarnya biaya administrasi yaitu 37 dan urutan ketiga nilai indeks tingkat kemudahan syarat pengajuan kredit yaitu 32,2. Pelayanan yang masih sangat kurang yaitu bonus bagi nasabah yang tepat waktu dalam membayar setoran memiliki nilai indeks 12,4. Menurut peternak besarnya bonus yang diberikan meningkatkan motivasi mereka dalam membayar setoran kredit tepat waktu sesuai perjanjian sehingga diharapkan tidak terjadi kredit macet.

Tabel 4. Tingkat Kepuasan Terhadap Pelayanan KPSBU

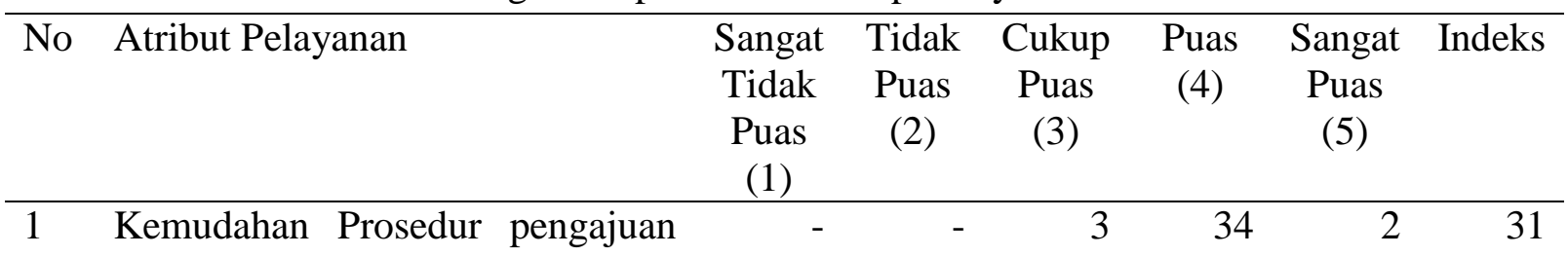




\begin{tabular}{llrrrrrr}
\hline & kredit sapi perah & & & & & \\
2 & Kemudahan syarat pengajuan & - & - & 5 & 24 & 10 & 32,2 \\
& kredit & & & & & & \\
3 & Tingkat suku Bunga & - & - & - & 6 & 33 & 38 \\
4 & Jangka waktu pencairan & - & - & 25 & 14 & & 26,2 \\
5 & Besarnya kredit & 3 & 2 & 18 & 12 & 4 & 25,8 \\
6 & Jangka waktu pinjaman & 4 & 6 & 20 & 14 & - & 26,4 \\
7 & Besarnya biaya administrasi & - & - & - & 10 & 29 & 37 \\
8 & Bonus bagi nasabah yg tepat & 16 & 23 & - & - & - & 12,4 \\
& waktu & & & & & & \\
9 & Kemudahan penyampaian keluhan & - & - & 5 & 29 & 5 & 31,2 \\
10 & Respon penyelesaian keluhan & - & 15 & 15 & 8 & 1 & 22,4 \\
11 & Pembinaan dan Pelatihan & - & 4 & 25 & 5 & 5 & 22,4 \\
12 & Penagihan kredit & - & - & 5 & 30 & 4 & 31 \\
13 & Sosialisasi kredit & - & 7 & 25 & 7 & - & 23,4 \\
14 & Jaminan kesehatan & - & 15 & 14 & 10 & - & 22,4 \\
15 & Pelayanan pinjaman uang & - & 19 & 10 & 10 & - & 21,6 \\
16 & Pelayanan waserda & - & - & 2 & 35 & 2 & 31,2 \\
\hline
\end{tabular}

\section{KESIMPULAN DAN IMPLIKASI KEBIJAKAN}

\section{Kesimpulan}

Kesimpulan dari penelitian ini adalah (1)Pemberian kredit kepada peternak dalam pengembangan usaha sapi perah dengan adanya bantuan kredit memberikan dampak positif. Hal ini terlihat dari laba yang diperoleh dan peningkatan produksi susu walaupun dalam uji statistik tidak berpengaruh nyata. (2)Produksi susu dipengaruhi oleh jumlah konsentrat, jumlah pakan hijauan, dan masa laktasi, akan tetapi jumlah kredit sapi, pengalaman dan pendidikan tidak berpengaruh nyata terhadap peningkatan produksi susu. (3) Sistem kelembagaan kredit sapi bergulir mandiri oleh KPSBU paling mudah dan singkat sedangkan sistem kelembagaan kredit perbankan paling sulit.

\section{Implikasi Kebijakan}

1. Hasil analisis usaha ternak menunjukan bahwa peternak sapi perah bankable terhadap program kredit sehingga perlu dijadikan sebagai sasaran penyaluran kredit dengan skala usaha jumlah kepemilikan kredit sapi perah 3 - 5 ekor.

2. Perlu penelitian lebih lanjut pada pengaruh besaran nilai kredit terhadap pengembangan skala usaha dan referensi kemudahan aksesibilitas kredit terhadap pendapatan usaha peternakan maupun pertanian.

\section{DAFTAR PUSTAKA}

Direktorat Jenderal Peternakan. 2008. Pusat Data dan Informasi Pertanian. http: www.ditjennak.go.id (diakses pada tanggal 16 Februari 2013.

Pembangunan Peternakan di Indonesia. Jakarta : Direktorat Jenderal Peternakan.http: www.ditjennak.go.id (diakses pada tanggal 16 Februari 2013).

KER Provinsi Jawa Barat, 2012. http : disnak.jabarprov.go.id (diakses pada tanggal 13 september 2013)

Doll John P dan Orazem Frank, 1984. Production Economics. Canada : printed in the United States of America Natzir M. 1999. Metodologi Penelitian. Cetakan ke-3. Jakarta: Ghalia Indonesia. 
Soekartawi, 2006. Teori Ekonomi Produksi Dengan Pokok

Bahasan Analisis Cobb-

Douglas. Jakarta : PT Raja

Grafindo Persada.
Sudono, A. 1999. Ilmu Produksi Ternak Perah.Diktat Kuliah.

Fakultas Peternakan Institut Pertanian Bogor, Bogor

Suyatno. 2003. Dasar-dasar Perkreditan. Jakarta : Gramedia. 
Lampiran 1. Tabel Produksi Penerimaan Untuk 4 Ekor Sapi Perperiode Laktasi

\begin{tabular}{|c|c|c|c|c|}
\hline Data & Satuan & Harga & Jumlah & Total \\
\hline Investasi & & & & $42,433,333.33$ \\
\hline Penerimaan & & $3,437.18$ & 14503.85 & $49,852,322.49$ \\
\hline \multicolumn{5}{|l|}{ Pengeluaran } \\
\hline \multicolumn{5}{|l|}{ Biaya Tetap } \\
\hline Penyusutan Kandang & Rp/Periode & & $310,096.15$ & \\
\hline Penyusutan Milk can & Rp/Periode & & $23,846.15$ & \\
\hline Penyusutan Ember Alm & Rp/Periode & & $17,692.31$ & \\
\hline Ember Plastik & Rp/Periode & & $41,025.64$ & \\
\hline Alat Kebersihan & Rp/Periode & & $55,256.41$ & \\
\hline Listrik & Rp/Periode & & $16,538.46$ & \\
\hline Sewa Lahan & Rp/Periode & & $7,456.41$ & \\
\hline Biaya Tetap Total & & & $471,911.54$ & $471,911.54$ \\
\hline \multicolumn{5}{|l|}{ Biaya Variabel } \\
\hline Tenaga Kerja & HOK/Periode & & $3,794,538.46$ & \\
\hline Konsentrat & Kg/Periode & & $19,135,384.62$ & \\
\hline Rumput & $\mathrm{Kg} /$ Periode & & $3,977,307.69$ & \\
\hline Obat \& Vit & $\mathrm{Mml} /$ perekor & & $1,176,923.08$ & \\
\hline IB & kali/ekor & & 83589.74359 & \\
\hline Biaya Variabel Total & & & $28,167,743.59$ & $28,167,743.59$ \\
\hline Biaya Total & & & $28,639,655.13$ & $28,639,655.13$ \\
\hline Biaya Variabel Rata -rata & & & $1,942.09$ & $1,942.09$ \\
\hline Cost / Unit & & & & $1,974.62$ \\
\hline Laba & & & & $21,212,667.36$ \\
\hline R/C Ratio & & & & 1.74 \\
\hline B/C Ratio & & & & 0.74 \\
\hline BEP unit & Liter & & & 315.66 \\
\hline BEP Rupiah & $\mathrm{Rp}$ & & & $1,084,913.21$ \\
\hline
\end{tabular}

